\title{
AUDIT OF SPECIAL MILK FORMULAE PRESCRIPTIONS IN PRIMARY CARE SETTING FOR FEED INTOLERANCE IN PAEDIATRIC POPULATION
}

\author{
S. Gautam ${ }^{1,2}$, N. Sutton ${ }^{3}$, C.P. Charlton ${ }^{1}$ \\ ${ }^{1}$ Queen's Medical Centre, Nottingham, ${ }^{2}$ East Midlands Deanery, Leicester, ${ }^{3}$ Nottingham City Hospital, \\ Nottingham, UK
}

Background \& aims: Specialised milk formulae are commonly prescribed in infants and children for feed intolerance. Our aim was to audit prescription of specialised milks for children in general practice population against the European Working Group guideline on management of cow's milk protein intolerance in infants.

Methods: Prescription details were obtained from the community pharmacy information team. 4 GP practices were randomly selected. Patients were identified by the participating practices from prescription records. Clinical data was then collected from practice records.

Results: No. Of patients - 58 Ages -3 months to 5 years

- $\quad 48 \%$ prescriptions were for Nutramigen Lipil follwed by Wysoy and SMA Lactose Free

- $70 \%$ of children prescribed Wysoy were below 1 yr of age

- $\quad 35 \%$ had at least 2 changes of formulae and $12 \%$ had more than 2 changes

- Vomiting, eczema and diarrhoea were most commonly recorded symptoms

- $48 \%$ were diagnosed with Cow's Milk Protein Intolerance, lactose intolerance (20\%) and gastrooesophageal reflux, dairy intolerance were amongst other diagnoses made

- $35 \%$ went through various investigations

- $40 \%$ of these children were referred to a dietitian and quarter were referred to a specialist

- $17 \%$ were documented to have been offered a rechallenge

Conclusion: Perceived feed intolerance in children proposes clinical challenge in primary care but appropriate diagnosis and management in liaison with dietetic support should lead to an improved patient care and cost effectiveness.

Acknowledgements: We are grateful to participating GP practices, community dietitian and pharmacy team for their cooperation in this study. 